\title{
Satu Data, Big Data dan Analatika Data: Urgensi Pelembagaan, Pembiasaan dan Pembudayaan
}

Agus Manshur

Perencana Ahli Madya di Direktorat Proyek Strategis Nasional, Kementerian PPN/Bappenas

Korespondensi: agus.manshur@bappenas.go.id

Doi: doi.org/10.47266/bwp.v4i1.82| halaman: 30-46

Dikirim: 26-08-2020 | Diterima: 18-03-2021 | Dipublikasikan: 31-03-2021

\begin{abstract}
Abstraksi
Ada beberapa istilah yang terkait dengan data seperti satu data, big data dan analitika data. Dalam memahami ketiga istilah tersebut ada potensi terjadi kesalahan tentang esensi dan fungsi yang sebenarnya dari data, khususnya data untuk mendukung formulasi kebijakan dan penyusunan perencanaan pembangunan. Satu data dimaksudkan sebagai tersedianya data yang akurat, mutakhir, terpadu, dapat dipertanggungjawabkan, serta mudah diakses dan dibagipakaikan antar instansi, baik pusat maupun daerah. Big data digunakan untuk menerangkan sebuah himpunan data (dataset) yang besar, berbeda-beda, kompleks dan/atau bersifat longitudinal yang dihasilkan dari berbagai macam instrumen, sensor dan/atau transaksi berbasis komputer. Analitika data mengacu kepada proses pengumpulan, pengaturan dan analisis terhadap himpunan data yang besar untuk menemukan pola-pola yang berbeda dan informasi yang penting. Dengan demikian, pelembagaan satu data, pembiasaan dan pembudayaan big data dan analitika data akan dapat mempertajam formulasi kebijakan dan perencanaan pembangunan dalam jangka panjang.
\end{abstract}

Kata kunci: satu data, big data, analitika data, formulasi kebijakan, perencanaan pembangunan. 


\title{
Satu Data, Big Data dan Analatika Data: Urgensi Pelembagaan, Pembiasaan dan Pembudayaan
}

\author{
Agus Manshur
}

\section{Pendahuluan}

Dalam dua tahun terakhir ini kita disibukkan dengan beberapa istilah yang semuanya berhubungan dengan data. Satu Data sebagai istilah singkat dari Satu Data Indonesia. Big Data yang kemudian terlalu cepat diterjemahkan menjadi Data Raya. Dan, Analitika Data yang sering dipertanyakan hubungannya dengan Analisis Data. Sekaliannya bersumber dan bermuara pada data. Namun, tetap saja ketiganya berpotensi untuk disalahfahami sekaligus disalahmengerti tentang esensi berikut fungsi sebenarnya dalam mendukung formulasi kebijakan dan penyusunan perencanaan pembangunan. Dalam kajian singkat ini penulis ingin mendudukkan persoalan ketiganya secara jelas sekaligus mengulas kemanfaatannya untuk kepentingan internal di Kementerian PPN/Bappenas.

Gagasan tentang Satu Data Indonesia berawal keresahan Presiden tentang sulitnya mendapatkan data yang benar ketika dibutuhkan pemerintah dalam merancang kebijakan publik yang strategis. Darisini muncul empat kemungkinan. Pertama, data yang dibutuhkan memang benar-benar tidak tersedia di kementerian/lembaga dan instansi daerah. Kedua, tersedia beberapa versi data untuk "objek data” yang sama di beberapa kementerian/lembaga dan instansi daerah, yang saling bertabrakan dan saling menegasikan satu sama lainnya. Ketiga, data yang tersedia diragukan validitas dan kualitasnya - terkait kaidah penyusunannya maupun regularitas pemutakhirannya - sehingga agak sulit dan dilematis untuk dijadikan bahan sebagai dasar pengambilan keputusan. Keempat, data yang tersedia tidak bisa saling diakses dan digunakan antar kementerian/lembaga ataupun antara pemerintah pusat dan pemerintah daerah.

Dengan melihat kompleksitas persoalan diatas kita dapat membayangkan jika urusan "per-data-an" kita selama ini memang parah. Karenanya jangan heran jika berkembang sarkasme di kalangan pemerintahan "ada banyak data tapi saat dibutuhkan tiba-tiba datanya tidak ada”. Kualitas, validitas, reliabilitas dan kontekstualitas data pemerintahan akhirnya dipertanyakan. Berbagai instansi pemerintah selama ini sibuk memproduksi data tanpa pernah mempertanyakan apakah kaidah penyusunannya sudah benar atau tidak sehingga valid digunakan sebagai bahan untuk pengambilan keputusan. Baik untuk formulasi kebijakan maupun exercise perencanaan pembangunan. Apabila kualitas dan validitas data rendah maka "garbage in garbage out" yang akan berlaku. Kita dapat membayangkan hasilnya, betapa kebijakan dan perencanaan pembangunan yang selama ini disusun juga "rendah" kualitas dan validitasnya. Pada akhirnya, proses bisnis dan siklus kebijakan publik akan menghukum kita di ujung karena semenjak dari awal kita telanjur dan terbiasa menggunakan "data sampah" dalam menganalisis persoalan sekaligus menyusun solusi atas persoalan tersebut dalam bentuk regulasi, kebijakan atau rencana pembangunan.

Berangkat dari persoalan diatas, pemerintah mulai berbenah diri dan kemudian menerbitkan Peraturan Presiden Nomor 9 Tahun 2019 tentang Satu Data Indonesia. Dalam peraturan ini ada dua substansi yang paling esensial, yaitu pertama, adanya perbaikan kaidah 
penyusunan data, dan kedua, adanya keinginan membangun fondasi kuat untuk mewujudkan praktik keterbukaan data (transparency) dan saling bagi pakai data (interoperability) diantara institusi pemerintahan.

Dalam konteks perbaikan kualitas data, menurut peraturan ini data yang digunakan sebagai dasar perencanaan pembangunan harus benar dan berkualitas. Data yang diproduksi baik data dasar maupun data yang digunakan sebagai pembentuk indikator perencanaan pembangunan - dalam bentuk indikator program, indikator kegiatan dan indikator keluaran (output) - seluruhnya harus sesuai prinsip Satu Data Indonesia. Pertama, harus menggunakan Standar Data yang benar. Kedua, harus memiliki Metadata yang baku. Ketiga, harus memiliki Kode Referensi dan Data Induk. Keempat, data yang telah diproduksi harus dapat dibagi pakaikan secara luas ke seluruh instansi pemerintah dan (bahkan) ke publik sehingga harus memiliki interoperabilitas yang tinggi melalui Portal Satu Data Indonesia.

Standar Data adalah terdiri dari konsep data, klasifikasi data (kuantitatif atau kualitatif), skala ukur data (nominal, ordinal, interval atau rasio), satuan data (misalnya kilometer, meter, hektar), dan definisi.

Metadata secara gampangnya dapat kita sebut sebagai "DNA" nya data. Artinya, informasi penting yang ada dibalik data tersebut harus disusun, baik konsep dan definisi data, metode perhitungan data, manfaat dari data, sumber data, disagregasi data (nasional, provinsi atau kabupaten/kota), maupun frekuensi penyusunan datanya (misalnya lima tahunan, tahunan atau bulanan).

Kode Referensi dan Data Induk adalah kode yang digunakan untuk menerangkan kode lembaga (kementerian/lembaga atau OPD di daerah), unit kerja eselon, program, kegiatan, keluaran dan sebagainya.

Interoperabilitas Data adalah keter-bagi-pakai-an data antar instansi pemerintah dalam Portal Satu Data Indonesia, yang secara teknis akan didukung oleh penerapan sistem pemerintahan berbasis elektronik. Oleh karena itu, data yang diproduksi harus konsisten dalam bentuk, struktur dan semantik serta dapat disimpan dalam format yang dapat dibaca sistem pendataan berbasis elektronik.

Dalam konteks keterbukaan dan keterbagipakaian data maka seluruh data yang telah memenuhi prinsip Satu Data Indonesia dan disepakati sebagai data prioritas yang harus ditampilkan di Portal Satu Data Indonesia menjadi terbuka untuk diakses seluruh instansi pemerintah dan masyarakat. Kecuali untuk data-data tertentu yang aksesnya diatur dan dibatasi, pada prinsipnya hampir semua data yang terdapat di Portal Satu Data Indonesia dapat diakses dan dibagipakaikan secara luas.

Singkatnya, pengaturan melalui Satu Data Indonesia bermaksud untuk mewujudkan penyelenggaraan tata kelola data yang dilakukan instansi pusat dan instansi daerah dalam menghasilkan data yang benar dan berkualitas untuk mendukung perencanaan, pelaksanaan, evaluasi dan pengendalian pembangunan. 


\section{Kajian Literatur}

\subsection{Big Data}

Pengertian atau definisi baku yang sering digunakan tentang Big Data adalah: kekayaan (aset) informasi yang memiliki volume besar, kecepatan tinggi dan variasi banyak, yang menuntut adanya bentuk-bentuk pengolahan informasi yang inovatif dan hemat biaya, yang dapat digunakan untuk meningkatkan wawasan dan kualitas pengambilan keputusan (Gartner, 2014). Namun demikian, terdapat beberapa definisi lain tentang Big Data yang diberikan oleh pakar maupun lembaga (lihat Tabel 1).

Tabel 1. Beberapa Definisi Tentang Big Data

\begin{tabular}{|l|c|l|}
\hline \multicolumn{1}{|c|}{ Sumber } & Tahun & \multicolumn{1}{|c|}{ Definisi } \\
\hline Loshin & 2009 & $\begin{array}{l}\text { Big Data adalah menerapkan teknik-teknik yang inovatif } \\
\text { dan hemat biaya untuk memecahkan masalah-masalah } \\
\text { bisnis saat ini dan di masa depan yang kebutuhan } \\
\text { sumberdayanya melebihi kemampuan dari komputasi } \\
\text { tradisional. }\end{array}$ \\
\hline Jacobs & 2009 & $\begin{array}{l}\text { Big Data adalah mengacu pada data yang ukurannya } \\
\text { memaksa kita untuk melihat melampaui metode-metode } \\
\text { "the 4 tried-and-true" yang sudah lazim kita kenal. }\end{array}$ \\
\hline $\begin{array}{l}\text { UN Global } \\
\text { Pulse (2012) }\end{array}$ & 2012 & $\begin{array}{l}\text { Big Data adalah frasa populer yang digunakan untuk } \\
\text { menggambarkan sebuah volume yang masif dari data yang } \\
\text { terstruktur dan data yang tidak terstruktur, yang } \\
\text { dikarenakan besarnya sulit untuk diproses dengan teknik- } \\
\text { teknik database dan software yang tradisional. Karakteristik } \\
\text { yang digunakan untuk membedakan Big Data dengan data } \\
\text { biasa adalah adanya 3-V atau Volume (isi) yang lebih besar, } \\
\text { Variety (variasi atau keragaman) yang lebih banyak dan } \\
\text { Velocity (kecepatan) yang lebih tinggi }\end{array}$ \\
\hline $\begin{array}{l}\text { Boyd } \\
\text { Crawford }\end{array}$ & 2012 & $\begin{array}{l}\text { Big Data adalah kapasitas untuk mencari, menggabungkan } \\
\text { dan mereferensi silang himpunan data yang sangat besar. }\end{array}$ \\
\hline Kraska & 2013 & $\begin{array}{l}\text { Big Data adalah ketika aplikasi normal dari teknologi yang } \\
\text { ada saat ini tidak memungkinkan pengguna untuk } \\
\text { mendapatkan jawaban yang tepat waktu, hemat biaya dan } \\
\text { berkualitas atas pertanyaan-pertanyaan yang berdasarkan } \\
\text { data. }\end{array}$ \\
\hline Wu et.al & 2014 & $\begin{array}{l}\text { Big Data adalag dimulai dengan sumberdaya bervolume } \\
\text { besar, heterogen dan otonom dengan control yang } \\
\text { terdistribusi dan terdesentralisasi serta berupaya untuk } \\
\text { mengeksplorasi hubungan yang kompleks dan } \\
\text { berkembang. }\end{array}$ \\
\hline
\end{tabular}

Sumber: diolah oleh penulis

Namun demikian, sebenarnya perdebatan tentang permasalahan, potensi, dan kemanfaatan Big Data bahkan sudah dilakukan puluhan tahun sebelumnya. Istilah atau terminologi tentang Big Data bahkan sudah menjadi kutipan-kutipan dalam pembahasan ilmiah dan perdebatan politik kenegaraan (terutama di Amerika Serikat) sejak tahun 1960an. Beberapa kutipan tentang Big Data dapat dilihat pada Tabel 2. 
Secara semantik, terminologi "Big Data" biasanya digunakan untuk menerangkan sebuah himpunan data (dataset) yang besar, berbeda-beda, kompleks dan/atau bersifat longitudinal yang dihasilkan dari berbagai macama instrumen, sensor dan/atau transaksitransaksi berbasis komputer (Megahed and Jones-Farmer, 2013). Selanjutnya, secara teknis, Big Data berlaku dan diterapkan untuk sekumpulan besar data mentah (terstruktur, semiterstruktur dan tidak terstruktur) yang tidak dapat diproses atau dianalisis dengan menggunakan perangkat atau metode tradisional, yang mengarah kepada meningkatnya tantangan dalam cara mengekstrak sebuah nilai (Zikopoulos et.al, 2012).

Tabel 2. Kutipan-Kutipan Tentang Big Data Selama Periode 1961-1979

\begin{tabular}{|c|c|c|}
\hline Sumber & Tahun & Kutipan-Kutipan \\
\hline US. Congress & 1961 & $\begin{array}{l}\text { "So I think it is quite important that we do not end up doing } \\
\text { a big data collecting job, with a quick, casual look at it and that } \\
\text { being the end of it" }\end{array}$ \\
\hline Kates & 1969 & $\begin{array}{l}\text { "Most of geographers are for big data banks, most support an } \\
\text { expanded range of census questions, most accept in some } \\
\text { vague general way the notion that the more we know about } \\
\text { the people the better off we are" }\end{array}$ \\
\hline DPMA & 1970 & $\begin{array}{l}\text { "Instead of big data dump where all information collected by } \\
\text { government agencies on all Americans would be gathered, he } \\
\text { proposes the following..." }\end{array}$ \\
\hline $\begin{array}{l}\text { Exemplary } \\
\text { Miller }\end{array}$ & 1971 & $\begin{array}{l}\text { "Eventually, the governance of data centers may fall into the } \\
\text { hands of those we know jokingly refer to as 'computerniks' } \\
\text { creating a danger that will be formulated by information } \\
\text { managers who so entranced with operating sophisticated } \\
\text { machines and manipulating large masses of data that they will } \\
\text { not be sufficiently sensitive to privacy considerations" }\end{array}$ \\
\hline US. Senate & 1972 & $\begin{array}{l}\text { "In actual fact, the practice has spawned big data centers } \\
\text { bureaucracies at tax payer expense. Industry claim millions of } \\
\text { dollar are wasted each year - as each federal agency tries to } \\
\text { build its own data empire" }\end{array}$ \\
\hline Merriam & 1974 & $\begin{array}{l}\text { "In the future, big data storage and retrieval systems will be } \\
\text { put into use" }\end{array}$ \\
\hline $\begin{array}{l}\text { Bassler dan } \\
\text { Joslin }\end{array}$ & 1976 & $\begin{array}{l}\text { "A big data center my handle several thousands tapes a day. } \\
\text { In addition to tracking the use of tapes and disks, the librarian } \\
\text { must be an expert the care and preservation of the tape and } \\
\text { disk media" }\end{array}$ \\
\hline Patrick & 1977 & $\begin{array}{l}\text { "More and more it is becoming apparent that a big data } \\
\text { processing system requires careful design attention to be } \\
\text { given both to the computer processing and the manual } \\
\text { processes such as data capture, balancing, error correction, } \\
\text { reports distribution that support the computer system" }\end{array}$ \\
\hline Muller & 1979 & $\begin{array}{l}\text { "The dreams of big data banks - that would even work - of } \\
\text { course raised public fears against the uncontrolled circulation } \\
\text { of personal information" }\end{array}$ \\
\hline
\end{tabular}

Sumber: Scholz (2017)

Seperti telah diterangkan diatas, pada awalnya konseptualisasi tentang Big Data dibangun dari tiga karakteristik utama, yaitu volume, velocity dan variety. Karakteristik pertama, menurut Zikopolous et.al (2012), yang merepresentasikan "Big" dalam Big Data adalah volume. Fenomena yang terjadi saat ini adalah adanya sebuah volume data yang 
meledak dengan beberapa organisasi yang terlibat dalam pengumpulan data sebesar satu terabyte setiap jam dan setiap harinya.

Karakteristik kedua, yaitu velocity. Menurut Porter et.al (2014) berhubungan dengan tingkat kecepatan pada saat data tiba, disimpan dan diambil untuk diproses. Dengan lebih banyaknya sensor yang tersedia, semakin banyaknya pengenalan perangkat yang terhubung, dan semakin banyaknya transaksi terkodifikasi yang terjadi secara global kita akan melihat peningkatan kecepatan dalam aliran data yang sangat pesat.

Karakteristik ketiga, yaitu variety. Menurut McAfee dan Brynjolfsson (2012), kemajuan teknologi yang ada telah memungkinkan pelacakan data dalam berbagai jenis media. Dalam fenomena ini kita juga melihat adanya perubahan-perubahan dalam variasi data. Diluar data numerik yang tradisional, saat ini kita melihat data mentah, data semiterstruktur dan data yang tidak terstruktur yang bersumber dari web pages, web log files, indeks pencarian, forum-forum media sosial, email, dokumen-dokumen, data sensor, gambar, rekaman video, sinyal GPS dan lain-lain.

Namun, ketiga karakteristik utama dari Big Data tersebut tidak cukup. Sebagai konsekuensi dari semakin berkembangnya fenomena Big Data, beberapa pakar mengusulkan untuk menambahkan karakteristik "V" yang lainnya. Morabito (2015) menunjukkan adanya konsensus yang berkembang di kalangan pakar untuk memasukkan karakteristik keempat yang relevan, yaitu veracity (kebenaran atau tingkat kepercayaan). Karakteristik veracity ini berhubungan dengan kualitas data.

Beberapa pakar yang lain menurut van Rijmenam (2014) berusaha membedakan konsistensi sebagai karakteristiknya sendiri sehingga pada akhirnya memasukkan karakteristik kelima, yaitu variability (hal yang berubah-ubah). Kesepakatan tersebut dipilih untuk menangani sifat data yang berubah-ubah. Dalam hal ini kita melihat bahwa definisi atau pengertian tentang data telah berubah. Hal ini disebabkan berkembangnya bentuk media (seperti blog, media sosial, dan video) yang menciptakan tantangan-tantangan baru dalam pengumpulan, pengkodifikasian dan penyimpanan dari berbagai data yang tidak terstruktur tersebut.

Dengan pemikiran yang sama, beberapa pakar berpendapat bahwa relevansi dari data adalah faktor penting yang lainnya. Biehn (2013) menunjukkan bahwa relevansi atau viability (kelangsungan hidup) tersebut menyangkut adanya kemungkinan data yang dianalisis dengan cara yang membuatnya relevan terhadap keputusan perusahaan atau organisasi. Di mana data yang terpilih untuk keperluan analisis cenderung dapat memperkirakan hasilhasil konsekuensi untuk perusahaan atau organisasi. Jadi, disepakati bahwa karakteristik utama keenam dari Big Data adalah viability.

Demikian pula, van Rijmenam (2014) juga menunjukkan beberapa pakar melihat bahwa visualisasi juga telah ditampilkan dan didefinisikan sebagai salah satu karakteristik utama dari Big Data yang signifikan. Visualisasi mengacu pada upaya membuat data yang secara komprehensif dapat difahami dengan cara yang gampang dimengerti. Oleh karena itu, visualization disepakati untuk dimasukkan sebagai karakteristik utama ketujuh dari Big Data.

Akhirnya, Marr (2015) menunjukkan bahwa elemen kedelapan sebagai karakteristik utama Big Data yang semakin mendapatkan perhatian dan terbukti paling menarik dari perspektif strategis para pakar adalah value dari Big Data. Intinya, faktor ini adalah tentang 
bagaimana data dapat dimanfaatkan untuk mendapatkan keuntungan secara finansial atau beberapa keuntungan lainnya seperti efisiensi operasional atau penciptaan pengetahuan. Jadi, value (nilai) adalah karakteristik terakhir dari Big Data. Untuk merangkumnya, kedelapan karakteristik utama Big Data diatas dapat digambarkan secara singkat pada Tabel 3.

Tabel 3. Karakteristik Utama Big Data

\begin{tabular}{|l|l|}
\hline Atribut & \multicolumn{1}{|c|}{ Penjelasan } \\
\hline Volume & Jumlah yang masif dari data yang dikumpulkan \\
\hline Velocity & $\begin{array}{l}\text { Tingkat di mana data tiba, disimpan dan diambil untuk } \\
\text { diproses }\end{array}$ \\
\hline Variety & Struktur dan bentuk data yang beragam \\
\hline Veracity & Tingkat kepercayaan dari data \\
\hline Variability & Sifat yang data yang berubah-ubah \\
\hline Viability & Relevansi dari data \\
\hline Visualization & Pemahaman dari data \\
\hline Value & $\begin{array}{l}\text { Data yang diterjemahkan kedalam proses belajar, penciptaan } \\
\text { pengetahuan, dan/atau manfaat ekonomis }\end{array}$ \\
\hline
\end{tabular}

Sumber: Mazzei and Noble (2019)

Dalam praktiknya, Big Data secara kompleks terhubung, secara teknis didukung dan secara keseluruhan menggunakan beberapa dimensi teknologi yang ada, yaitu data mining (penambangan data), algorithm (algoritma), machine learning (pembelajaran mesin) dan artificial intelligence (kecerdasan buatan). Namun, Big Data tidak bisa serta merta dikategorikan dan dibatasi hanya kedalam dimensi teknologi tersebut. Justru, Big Data memungkinkan seluruh dimensi teknologi tersebut menjadi lebih baik dan terhubung dalam kesatuan proses (Lohr,2012; O'Leary, 2013). Secara sederhana, Scholz (2017) menggambarkan keterhubungan Big Data dengan seluruh dimensi terknologi tersebut kedalam siklus teknologi (lihat Gambar 1).

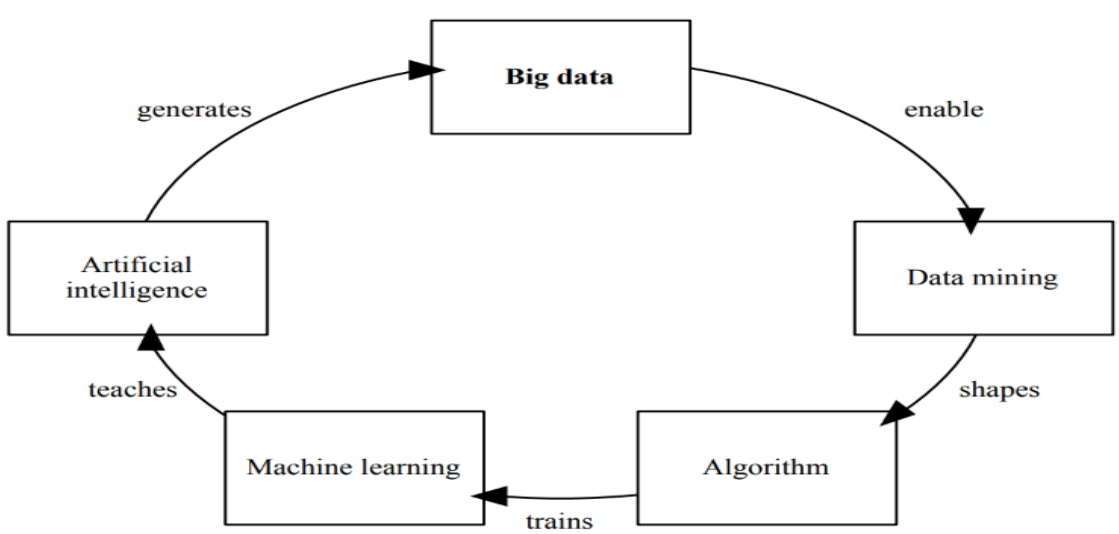

Gambar 1. Siklus Teknologi Big Data Sumber: Scholz (2017) 


\subsection{Analitika Data}

Analitika Data seringkali disalahartikan dengan Analisis Data padahal keduanya memiliki arti dan penggunaan yang berbeda (lihat Tabel 4). Analitika Data menurut Rihai dan Rihai (2016) mengacu kepada proses pengumpulan, pengaturan dan analisis terhadap himpunan data yang besar untuk menemukan pola-pola yang berbeda dan informasi yang penting lainnya. Analitika Data adalah suatu himpunan dari teknologi dan teknik yang memerlukan bentuk-bentuk baru dari perpaduan untuk mengungkapkan nilai-nilai besar yang tersembunyi dari himpunan data yang besar yang berbeda dari biasanya, lebih kompleks dan dalam skala yang besar. Oleh karena itu, Analitika Data terutama memfokuskan pada pemecahan masalah-masalah baru atau masalah lama dengan cara-cara yang lebih baik dan efektif. Sampai saat ini dikenal adanya empat jenis Analitika Data dengan kegunaan masing-masing (lihat Tabel 5).

Tabel 4. Data Analytics versus Data Analysis

\begin{tabular}{|c|c|c|}
\hline Aspects & Data Analytics & Data Analysis \\
\hline Form & $\begin{array}{l}\text { Data analytics is general form of analytics } \\
\text { which is used in businesses to make } \\
\text { decision from data which are data driven. }\end{array}$ & $\begin{array}{l}\text { Data analysis is a specialized form of } \\
\text { data analytics used in businesses to } \\
\text { analyse data and take some insights of } \\
\text { it. }\end{array}$ \\
\hline Structure & $\begin{array}{l}\text { Data analytics consist of data collection } \\
\text { and inspect in general and it has one or } \\
\text { more usage. }\end{array}$ & $\begin{array}{l}\text { Data analysis consist of defining a } \\
\text { data, investigation, cleaning, } \\
\text { transforming the data to give a } \\
\text { meaningful outcome. }\end{array}$ \\
\hline Tools & $\begin{array}{l}\text { There are many analytics tools in market } \\
\text { but mainly R, Tableau Public, Phyton, } \\
\text { SAS, Apache Spark, Excel are used. }\end{array}$ & $\begin{array}{l}\text { For analyse the data OpenRefine, } \\
\text { KNIME, RapidMiner, Google Fusion } \\
\text { Tables, Tableau Public, NodeXL, } \\
\text { WolframAlpha tools are used. }\end{array}$ \\
\hline Sequence & $\begin{array}{l}\text { Data analytics life cycle consist of } \\
\text { Business Case Evaluation, Data } \\
\text { Identification, Data Acquisition and } \\
\text { Filtering, Data Validation and Cleansing, } \\
\text { Data Aggregation and Representation, } \\
\text { Data Analysis, Data Visualization, } \\
\text { Utilization of Analysis Results. }\end{array}$ & $\begin{array}{l}\text { Sequence followed in data analysis are } \\
\text { data gathering, data scrubbing, } \\
\text { analysis of data and interpret the data } \\
\text { precisely so that you can understand } \\
\text { what your data want to say. }\end{array}$ \\
\hline Usage & $\begin{array}{l}\text { Data Analytics in general can be used to } \\
\text { find masked patterns, anonymous } \\
\text { correlations, market trends and other } \\
\text { necessary information that can help to } \\
\text { make more notify decisions for business } \\
\text { purpose. }\end{array}$ & $\begin{array}{l}\text { Data Analysis can be used in various } \\
\text { ways like one can perform analysis like } \\
\text { descriptive analysis, exploratory } \\
\text { analysis, inferential analysis, } \\
\text { predictive analysis, and take useful } \\
\text { insights from the datar. }\end{array}$ \\
\hline Example & $\begin{array}{l}\text { Let say you have } 1 \text { gb customer purchase } \\
\text { related data of past } 1 \text { year, now one has } \\
\text { to find that we are customers next } \\
\text { possible purchases, you will use data } \\
\text { analytics for that. }\end{array}$ & $\begin{array}{l}\text { Suppose you } 1 \text { gb customer purchased } \\
\text { related data of past } 1 \text { year and you are } \\
\text { try to find what happened so far that } \\
\text { means in data analysis we look into } \\
\text { past. }\end{array}$ \\
\hline
\end{tabular}

Sumber: EDUCBA (2019) 
Tabel 5. Jenis-Jenis Analitika Data

\begin{tabular}{|c|c|c|c|}
\hline Jenis Analitika & $\begin{array}{l}\text { Pertunjuk } \\
\text { Pertanyaan }\end{array}$ & Pengertian Singkat & Kegunaan \\
\hline $\begin{array}{l}\text { Analitika } \\
\text { Deskriptif }\end{array}$ & $\begin{array}{l}\text { Untuk menjawab: } \\
\text { Apa yang terjadi? }\end{array}$ & 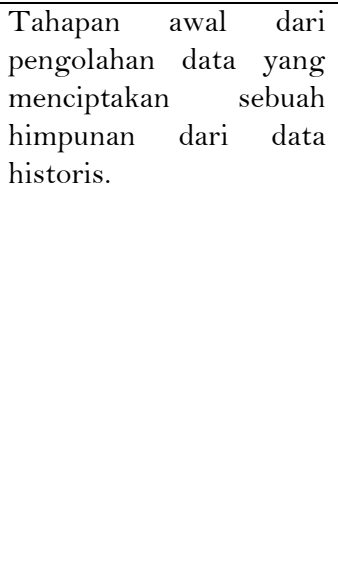 & $\begin{array}{lr}\text { Metode-metode } & \text { Data } \\
\text { Mining akan mengatur } & \text { m } \\
\text { data dan } & \text { membantu } \\
\text { mengungkap } & \text { pola-pola } \\
\text { yang akan } & \text { akan } \\
\text { memberikan } & \text { sebuah } \\
\text { wawasan. } & \text { Analitika } \\
\text { Deskriptif menyediakan } \\
\text { kemungkinan- } \\
\text { kemungkinan dan tren- } \\
\text { tren masa depan serta } \\
\text { memberikan } \\
\text { gagasan tentang apa yang } \\
\text { mungkin terjadi di masa } \\
\text { depan. }\end{array}$ \\
\hline $\begin{array}{l}\text { Analitika } \\
\text { Diagnostik }\end{array}$ & $\begin{array}{lr}\text { Untuk menjawab: } \\
\text { Mengapa hal itu } \\
\text { terjadi? }\end{array}$ & $\begin{array}{l}\text { Pencarian akar penyebab } \\
\text { dari suatu masalah. }\end{array}$ & \begin{tabular}{lr} 
Analitika & \multicolumn{2}{r}{ Diagnostik } \\
biasanya digunakan & untuk \\
menentukan & mengapa \\
sesuatu terjadi. & Jenis \\
analitika ini & dapat \\
digunakan & untuk \\
menemukan & dan \\
memahami & sebab-sebab \\
dari peristiwa dan perilaku.
\end{tabular} \\
\hline $\begin{array}{l}\text { Analitika } \\
\text { Prediktif }\end{array}$ & $\begin{array}{l}\text { Untuk menjawa: } \\
\text { Apa yang mungkin } \\
\text { terjadi? }\end{array}$ & $\begin{array}{l}\text { Menggunakan data masa } \\
\text { lalu dalam kerangka } \\
\text { untuk memperkirakan } \\
\text { masa depan. Semua yang } \\
\text { berhubungan dengan } \\
\text { peramalan. }\end{array}$ & $\begin{array}{l}\text { Analitika } \\
\text { menggunakan breskriptif } \\
\text { Teknik seperti Danyak } \\
\text { Mining } \\
\text { dan Artificial Intelligence } \\
\text { untuk menganalisis data } \\
\text { saat ini dan membuat } \\
\text { skenario dari apa yang } \\
\text { akan mungkin terjadi. }\end{array}$ \\
\hline $\begin{array}{l}\text { Analitika } \\
\text { Preskriptif }\end{array}$ & $\begin{array}{l}\text { Untuk menjawab: } \\
\text { Apa yang dilakukan? }\end{array}$ & $\begin{array}{lr}\text { Didedikasikan untuk } \\
\text { menemukan aksi yang } \\
\text { tepat yang } & \text { perlu } \\
\text { dilakukan. } & \end{array}$ & $\begin{array}{l}\text { Analitika Preskriptif } \\
\text { menyediakan data historis } \\
\text { dan analitika prediktif } \\
\text { untuk membantu } \\
\text { meramalkan apa yang } \\
\text { mungkin terjadi. Analitika } \\
\text { Preskriptif menggunakan } \\
\text { parameter-parameter ini } \\
\text { untuk menemuka solusi } \\
\text { yang terbaik. }\end{array}$ \\
\hline
\end{tabular}

Sumber: diolah dan diadopsi penulis dari Rihai dan Rihai (2016) 


\section{Pembahasan}

\subsection{Pelembagaan Satu Data Kedalam Proses Perencanaan}

Pelembagaan Satu Data Indonesia kedalam proses perencanaan pembangunan berarti memasukkan produksi data yang diperlukan dalam perencanaan pembangunan (terutama untuk penyusunan RPJMN dan RKP) kedalam siklus reguler perencanaan pembangunan di Kementerian PPN/Bappenas. Dalam hal ini yang dimaksud produksi data adalah penyediaan data yang sudah memenuhi prinsip Satu Data Indonesia, yang diperlukan dan digunakan sejak dalam proses kajian kebijakan, penyusunan kebijakan dan rencana serta pemantauan, evaluasi dan pengendalian pembangunan. Secara ringkas proses tersebut dapat dilihat pada Gambar 2.

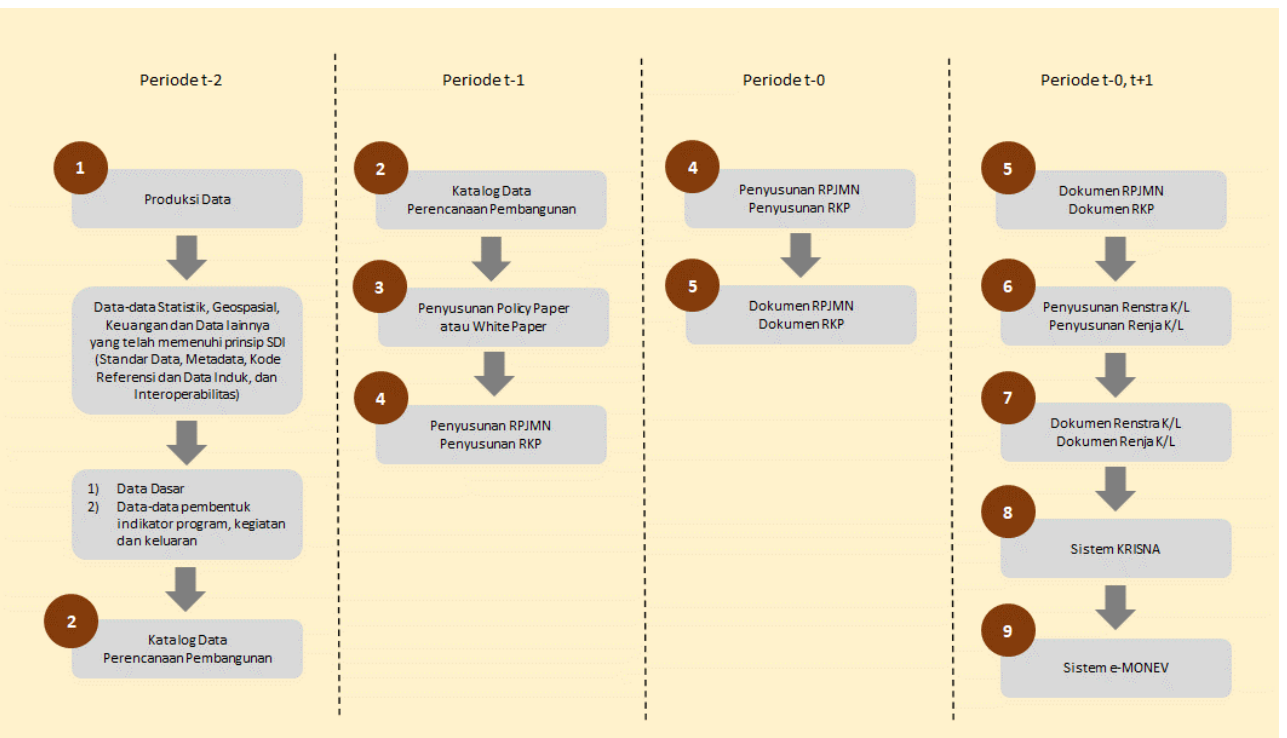

Gambar 2. Proses Pelembagaan Satu Data Kedalam Siklus Reguler Perencanaan Pembangunan

Dari Gambar 2 diatas kita dapat melihat bahwa terdapat periodesasi proses yang dibagi kedalam empat tahapan. Pada Periode t-2 seluruh Direktorat teknis di Bappenas harus melakukan proses Produksi Data yang benar, berkualitas dan memenuhi prinsip Satu Data Indonesia, yang selanjutnya keluaran dari proses Produksi Data tersebut adalah Katalog Data Perencanaan Pembangunan (Katalog Data Renbang). Dalam proses penyusunan Katalog Data Renbang, Direktorat teknis di Bappenas akan difasilitasi dan dipandu oleh Pusdatinrenbang yang bertindak sebagai Walidata Kementerian PPN/Bappenas (akan dijelaskan dalam bagian terpisah).

Selanjutnya, pada Periode t-1 Katalog Data Renbang tersebut digunakan sebagai dasar dalam Penyusunan Naskah Kebijakan (Policy Paper atau White Paper) yang mendasari proses Penyusunan Rencana Pembangunan (RPJMN dan RKP).

Pada Periode t-o data yang digunakan dalam proses Penyusunan RPJMN dan RKP berasal dari Katalog Data Renbang yang notabene sudah benar, berkualitas dan memenuhi prinsip Satu Data Indonesia. Pada periode ini pula data yang digunakan baik sebagai data dasar maupun data pembentuk indikator program, kegiatan dan keluaran dalam dokumen 
RPJMN dan RKP juga sudah benar, berkualitas dan memenuhi prinsip Satu Data Indonesia. Pada periode ini pula secara hampir bersamaan Kementerian/Lembaga menyusun Renstra dan Renja K/L berdasarkan rancangan dokumen RPJMN dan RKP. Sama seperti proses internal di Bappenas, sebelum menyusun dokumen Renstra dan Renja K/L maka Kementerian/Lembaga harus pula menyusun Katalog Data Perencanaan Pembangunan Sektoral (Katalog Data Renbang Sektoral) yang sudah benar, berkualitas dan memenuhi prinsip Satu Data Indonesia.

Dalam penyusunan Katalog Data Renbang Sektoral, Kementerian/Lembaga yang diwakili oleh Pusdatin di setiap K/L (sebagai Walidata K/L) akan memfasilitasi dan memandu seluruh unit kerja eselon II yang terlibat dalam penyusunan Renstra dan Renja K/L. Sebagai bagian dari proses pembinaan perencanaan pembangunan maka Direktorat teknis di Bappenas akan melakukan knowledge sharing terhadap seluruh Pusdatin di K/L dan unit kerja eselon II yang menjadi mitranya. Dengan proses ini diharapkan Katalog Data Renbang Sektoral yang dihasilkan seluruh kementerian/Lembaga sudah benar, berkualitas dan memenuhi prinsip Satu Data Indonesia.

Akhirnya, pada periode $\mathbf{t}+\mathbf{1}$ dokumen Renja K/L dari seluruh kementerian/lembaga yang dimasukkan kedalam Sistem KRISNA datanya - untuk membentuk indikator program, kegiatan dan keluaran - sudah benar, berkualitas dan memenuhi prinsip Satu Data Indonesia. Selanjutnya, dokumen Renja K/L yang dimasukkan kedalam Sistem e-Monev (yang sebelumnya diimpor dari Sistem KRISNA) sudah memiliki data indikator program, kegiatan dan keluaran yang sudah benar, berkualitas dan memenuhi prinsip Satu Data Indonesia pula.

\subsection{Fasilitasi dan Knowledge Sharing Penyusunan Katalog Data}

Ilustrasi proses dan tahapan yang diterangkan pada Gambar 2 diatas adalah merupakan proses dan tahapan yang ideal. Artinya, untuk saat ini hal tersebut belum terjadi dan berjalan secara sistemik. Untuk mewujudkan idealita tersebut secara internal di Bappenas maka seluruh Direktorat teknis secara bersama-sama harus segera memulai proses penyusunan Katalog Data Renbang yang benar, berkualitas dan memenuhi prinsip Satu Data Indonesia.

Untuk menghasilkan Katalog Data Renbang yang benar, berkualitas dan memenuhi prinsip Satu Data Indonesia maka Pusdatinrenbang sebagai Walidata Kementerian PPN/Bappenas harus melakukan fasilitasi, pemanduan (coaching) sekaligus knowledge sharing kepada seluruh Direktorat teknis di Bappenas. Kegiatan ini memiliki tujuan ganda.

Pertama, memastikan bahwa seluruh Direktorat teknis di Bappenas telah memahami proses penyusunan Katalog Data Renbang yang didalamnya sudah terdapat Standar Data, Metadata, Kode Referensi dan Data Induk dan Interoperabilitas (atau memenuhi prinsip Satu Data Indonesia). Pemahaman terhadap Standar Data, Metadata, Kode Referensi dan Data Induk serta Interoperabilitas ini sangat penting dan mendasar dalam menyusun Katalog Data Renbang.

Kedua, memastikan pada tahap berikutnya seluruh Direktorat teknis di Bappenas dapat meneruskan (penerusan pengetahuan) proses fasilitasi, pemanduan dan knowledge sharing tentang penyusunan Katalog Data Renbang kepada seluruh Pusdatin K/L dan unit kerja eselon II yang menjadi mitranya masing-masing. Dengan demikian, dalam hal ini terjadi proses fasilitasi, pemanduan dan knowledge sharing yang berjenjang, sistemik dan 
berkelanjutan sehingga pada tahap berikutnya seluruh Katalog Data Renbang Sektoral dari kementerian/lembaga kualitasnya sama. Untuk menyederhanakan penjelasan diatas proses tersebut dapat diterangkan dalam Gambar 3.

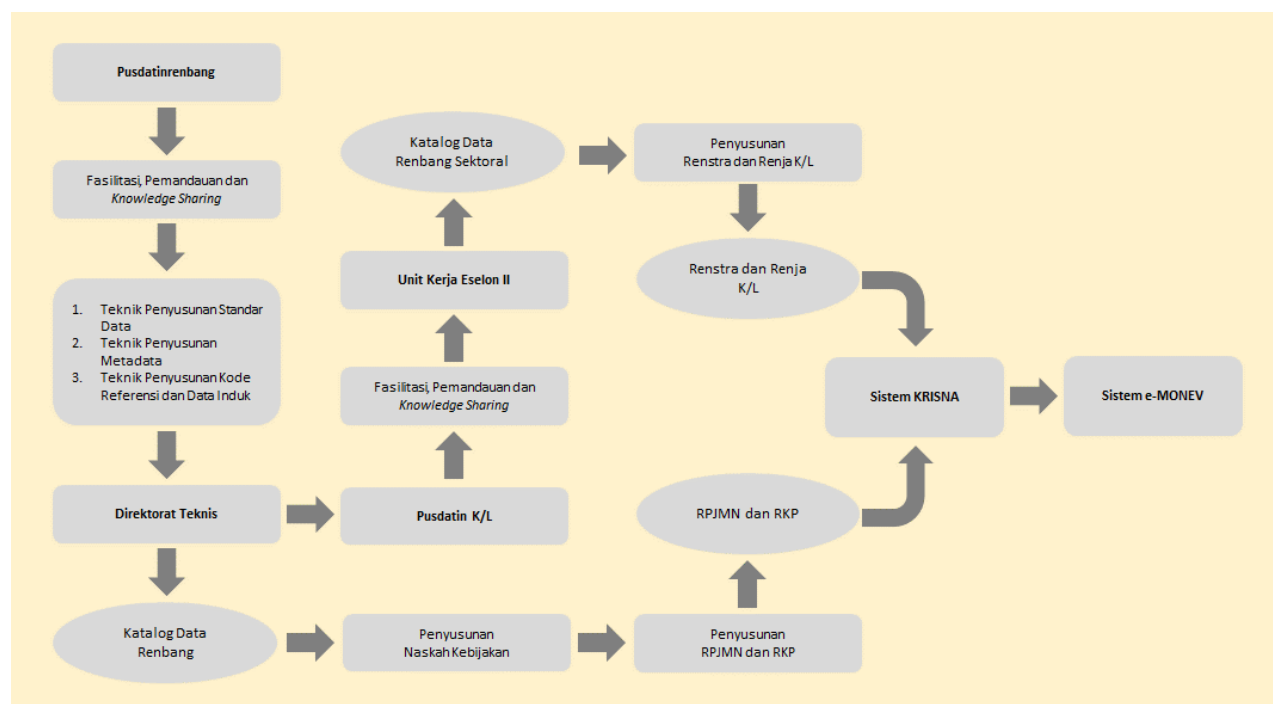

Gambar 3. Proses Fasilitasi, Pemanduan dan Knowledge Sharing Penyusunan Katalog Data Renbang

\subsection{Pembiasaan dan Pembudayaan Praktik Analitika Data}

Dalam konteks pemanfaatan Big Data melalui penerapan Analitika Data di Bappenas maka sebelumnya harus difahami dahulu prasyarat-prasyarat yang harus dipenuhi. Pemanfaatan Big Data secara substansial memerlukan terpenuhinya terlebih dahulu prasyarat-prasyarat sebagai berikut: 1) pemahaman tentang Big Data secara benar, 2) pemahaman dan penguasaan tentang Analitika Data, 3) penyediaan sumberdaya yang kompeten, memiliki kapasitas dan kapabilitas, 4) penyediaan fasilitas dan infrastruktur pendukung yang memadai, 5) pelembagaan pemanfaatan Big Data secara sistemik dan berkelanjutan. Prasyarat-prasyarat tersebut akan dijelaskan satu per satu sesuai pemetaan terhadap kondisi kekinian di Bappenas.

Big Data dan Analitika Data masih merupakan "barang baru" di kalangan pimpinan dan staf di Bappenas sehingga belum menjadi kebiasaan (habbit) apalagi budaya (culture) dalam proses bekerja sehari-hari. Oleh karena itu, "orang Bappenas" terlebih dahulu harus benar-benar memahami tentang Big Data dengan benar. Selanjutnya, menguasai penerapan Analitika Data secara tepat. Pemahaman yang benar tentang Big Data diperlukan agar tidak terjadi kekacauan logika berfikir untuk secara serta merta memasukkan Big Data kedalam proses formulasi kebijakan dan perencanaan pembangunan.

Seperti yang dijelaskan pada bagian sebelumnya, Big Data berisi data yang sangat besar volumenya baik data terstruktur, semi-terstruktur maupun yang tidak terstruktur yang bersumber dari manapun. Sementara, proses formulasi kebijakan dan terutama perencanaan pembangunan memerlukan data yang terstruktur sesuai dengan prinsip Satu 
Data Indonesia. Oleh karena itu, pemanfaatan Big Data kedalam proses formulasi kebijakan dan perencanaan pembangunan memerlukan bantuan penerapan Analitika Data supaya seluruh data yang akan digunakan dapat distrukturkan terlebih dahulu sehingga dapat digunakan dengan tepat dan efektif (lihat Gambar 4).

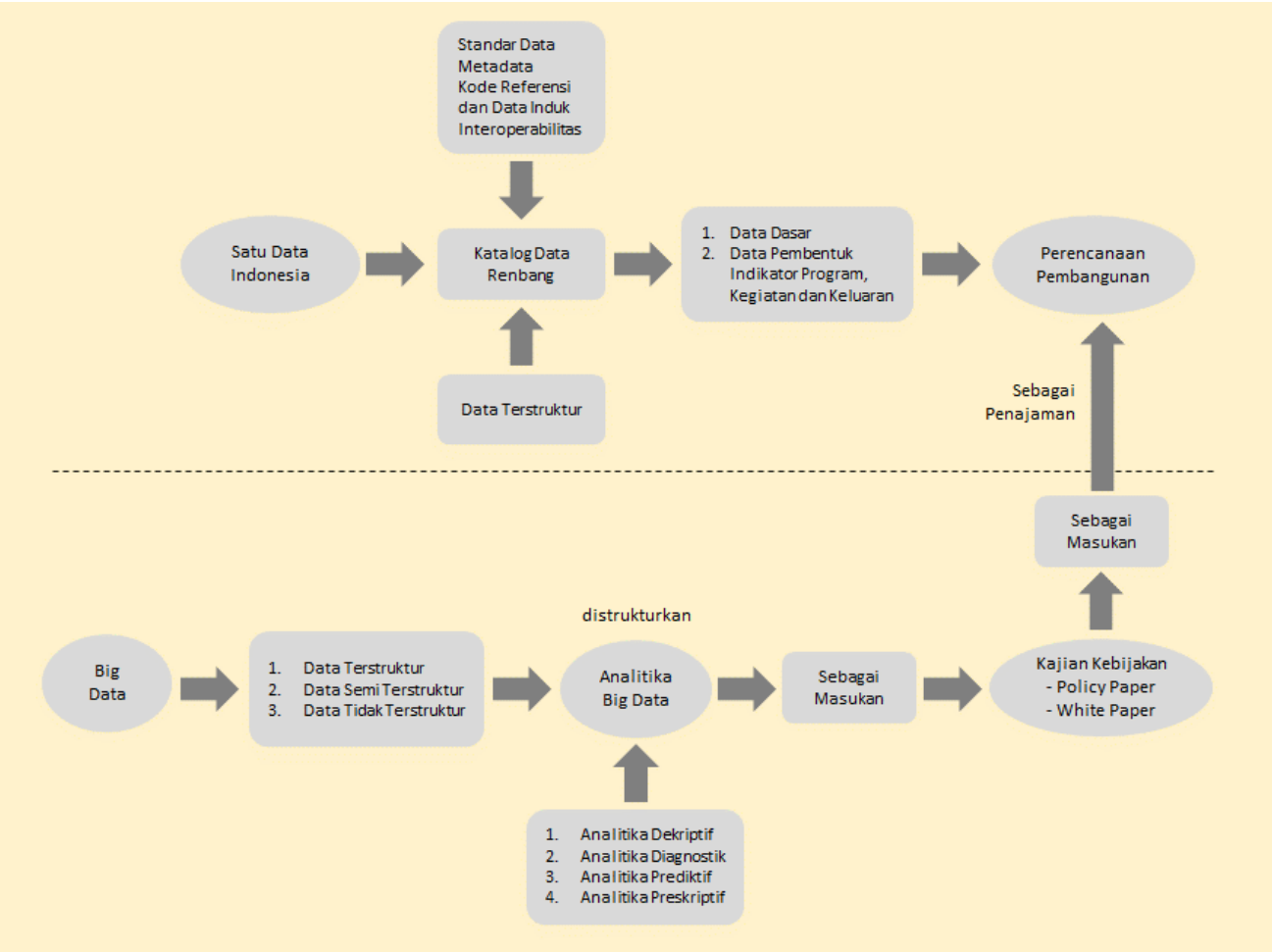

Gambar 4. Pemanfaatan Big Data dan Analitika Data Dalam Mendukung Perencanaan Pembangunan

Tahap berikutnya adalah pemahaman dan penguasaan Analitika Data. Secara faktual, sampai saat ini belum banyak "orang Bappenas" yang sudah faham sekaligus bisa menguasai Analitika Data untuk memanfaatkan Big Data dalam keseharian pelaksanaan tugas-tugas di Bappenas. Untuk mengantisipasi hal tersebut, sejak akhir tahun lalu Pusdatinrenbang telah membentuk Tim Analitika Bappenas (dengan SK Menteri). Pembentukan tim ini merupakan investasi awal yang dilakukan agar staf Bappenas perlahan-lahan mulai memahami Big Data dan Analitika Data serta mempraktikkan Analitika Data untuk memanfaatkan dan mengolah Big Data untuk keperluan di Bappenas (lihat Gambar 5).

Dalam komposisinya, Tim Analitika Bappenas terdiri dari perwakilan dari masingmasing Kedeputian teknis yang memiliki mitra K/L, perwakilan dari unit kerja eselon II dibawah Sesmen/Sestama yang tupoksinya sesuai, dan perwakilan dari Pusdatinrenbang. Dalam perencanaannya, diharapkan apabila Tim Analitika Bappenas sudah memiliki kompetensi, kapasitas dan kapabilitas serta fasih dan teruji dalam menggunakan Analitika Data untuk memanfaatkan dan mengolah Big Data maka dalam jangka menengah secara 
kelembagaan dapat ditransformasikan kedalam pembentukan Unit Analitika Bappenas dibawah Menteri secara langsung. Dengan perencanaan seperti ini diharapkan kita dapat menjawab butir kelima dari prasyarat diatas.

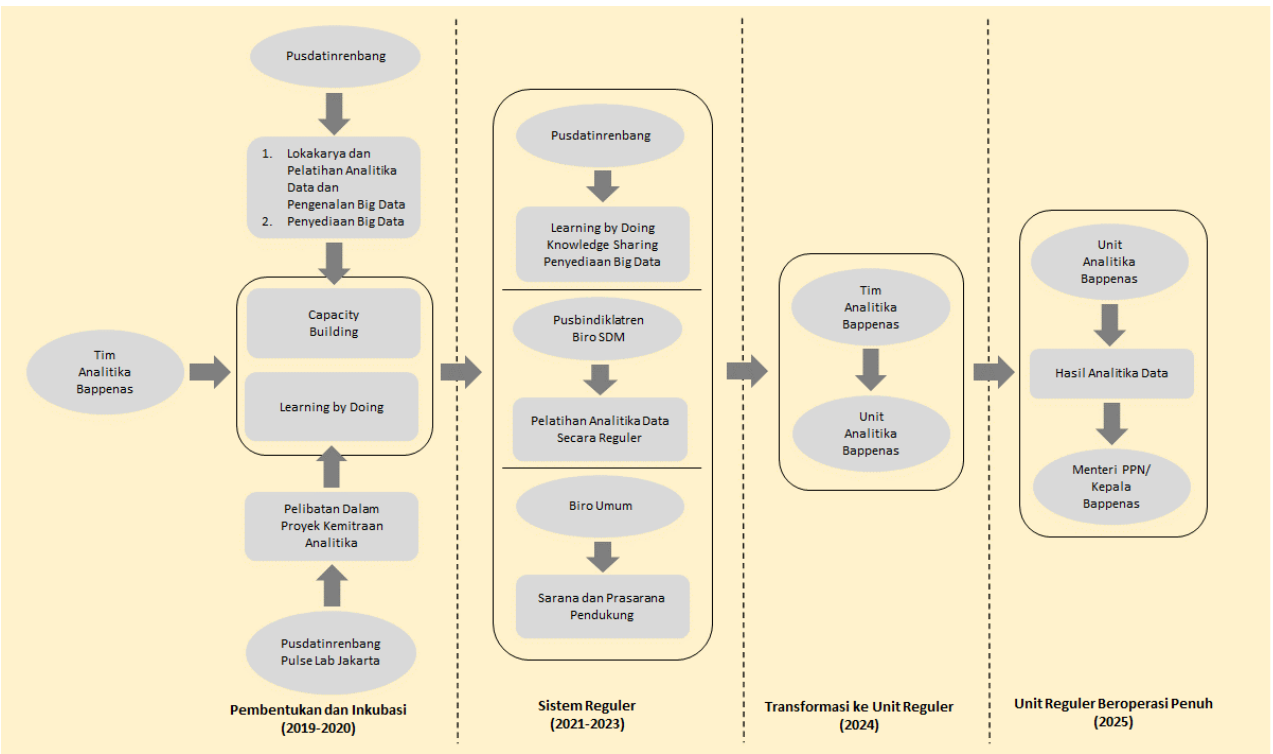

Gambar 5. Peta Jalan Sederhana Pengembangan Tim Analitika Bappenas

Untuk mewujudkan harapan diatas, Pusdatinrenbang tahun ini mulai menginisiasi Lokakarya dan Pelatihan Analitika Data dan Pengenalan Big Data untuk perwakilan dari Tim Analitika Bappenas mulai dari tingkat dasar, menengah dan lanjutan. Lokakarya dan Pelatihan ini diharapkan mulai tahun depan sudah diadopsi menjadi kegiatan reguler Pusbindiklatren Bappenas dan Biro Sumberdaya Manusia, Bappenas yang akan diselenggarakan setiap tahunnya untuk seluruh anggota Tim Analitika Bappenas sehingga kompetensi, kapasitas dan kapabilitas tim ini akan terus menerus meningkat dari tahun ke tahun. Inilah "PR" pengembangan kapasitas (capacity building) yang secara sistemik dan berkelanjutan harus terus menerus dilakukan di Bappenas. Dengan "continuous capacity building" tersebut maka kita dapat menjawab sekaligus butir pertama, kedua dan ketiga dari prasyarat diatas.

Sementara, untuk menjawab butir keempat prasyarat diatas Pusdatinrenbang selama ini sudah menyediakan Big Data melalui sewa layanan untuk data-data ekonomi seperti Bloomberg dan CIC dan data media massa nasional melalui Intelligence Media Management (IMM). Untuk data yang bersumber dari media sosial seperti Twitter, Pusdatinrenbang ulai tahun depan sudah bisa menyediakannya secara reguler setiap tahunnya. Sementara, untuk akses terhadap seluruh data dari Badan Pusat Statistik (BPS), Pusdatinrenbang selama ini sudah memiliki kerjasama khusus dengan BPS sehingga seluruh staf Bappenas dapat mengakses seluruh data BPS secara gratis dengan syarat menandatangani dokumen Letter Agreement Data Use (LADU) terlebih dahulu. 
Di sisi lain, sejak tahun 2012 Pusdatinrenbang bekerja sama dan bermitra dengan Pulse Lab Jakarta (PLJ) untuk mengembangkan inovasi data dalam mendukung pertumbuhan inklusif dan pembangunan berkelanjutan. Sejak akhir 2019, Pusdatinrenbang dan PLJ sepakat untuk melakukan revitalisasi dan reorientasi substansial dan mempertajam program dan kegiatannya yang tidak hanya sekedar memfokuskan pada pengembangan inovasi data tetapi secara luas akan memfasilitasi dan mengembangkan kemitraan analitika yang dibutuhkan dan diusulkan unit kerja eselon II, Bappenas, kementerian/lembaga, BUMN, pemerintah daerah dan BUMD untuk secara bersama-sama mempraktikkan dan mengembangkan analitika yang mendukung terwujudnya pertumbuhan inklusif dan pembangunan berkelanjutan tersebut. Mulai tahun ini, tata kelola (governance) dalam pengembangan kemitraan analitika sudah disempurnakan dan mulai dipraktikkan Pusdatinrenbang dan PLJ.

Tahun ini terdapat lima proyek kemitraan analitika yang sedang difasilitasi Pusdatinrenbang dan PLJ, yaitu 1) pengembangan analitika transportasi kereta penumpang jarak jauh dengan PT. Kereta Api Indonesia, 2) pengembangan analitika perbaikan tingkat kesejahteraan ASN dengan Lembaga Administrasi Negara, 3) pengembangan analitika portal analisa berita diplomatik dengan Kementerian Luar Negeri, 4) pengembangan analitika dashboard dan aplikasi kebencanaan dengan Direktorat Daerah Tertinggal, Transmigrasi dan Perdesaan, Bappenas, dan 5) pengembangan dashboard tracking Covid-19 di perdesaan dengan Dinas Kominfo, Jawa Barat.

Kelima proyek kemitraan analitika tersebut dalam praktiknya dikerjakan bersamasama secara tripartit yang melibatkan pihak pengusul proyek, Pusadatinrenbang dan PLJ. Disamping itu, sebagai wadah dan proses pembelajaran, dalam implementasi proyek-proyek tersebut juga melibatkan perwakilan dari Tim Analitika Bappenas (sesuai substansi proyek), staf dari Direktorat teknis terkait (sesuai substansi proyek) dan Tim Analitika internal Pusdatinrenbang sebagai satu kesatuan kelompok kerja (working group). Proses pelibatan dalam implementasi proyek kemitraan analitika ini dimaksudkan sebagai perwujudan dari learning by doing untuk memahami sekaligus mempraktikkan Analitika Data secara sekaligus.

Dengan hampir terpenuhinya seluruh prasyarat diatas (secara relatif) maka pembiasaan praktik Analitika Data di Bappenas akan dapat dijalankan secara lebih cepat sehingga praktik Analitika Data akan menjadi sebuah kebiasaan (habbit) yang baru di Bappenas dalam jangka menengah. Untuk mendukung dan mengembangkan kebiasaan baru tersebut mau tidak mau Pusdatinrenbang, Pusbindiklatren, Biro Sumberdaya Manusia dan Biro Umum harus mampu menjadi "enabler" dalam menyediakan "enabling environment" secara terus menerus dan berkelanjutan. Penyediaan sarana dan prasarana serta pengembangan kapasitas (capacity building) harus terus menerus diimplementasikan untuk menjaga agar kebiasaan baru ini semakin tumbuh dan berkembang.

Apabila kebiasaan baru ini dapat terus menerus dipraktikkan dan dikembangkan di Bappenas maka dalam jangka panjang akan menciptakan sebuah budaya (culture) baru yang akan berdampak positif bagi penguatan kelembagaan Bappenas secara keseluruhan. Pada titik inilah kita akan melihat bahwa Bappenas secara kelembagaan tidak akan lagi terkagetkaget dan terkagum-kagum dengan pesona sekaligus "sihir" Big Data dan Analitika Data semata tetapi Bappenas sudah mampu memanfaatkan, menundukkan sekaligus menguasai 
Big Data dan Analitika Data untuk mempertajam penyusunan kebijakan yang mendukung perencanaan pembangunan yang berkualitas.

\section{Penutup}

Pelembagaan Satu Data Indonesia kedalam proses dan siklus perencanaan pembangunan di Bappenas merupakan urgensi yang harus dilakukan. Hal ini untuk meningkatkan kualitas dokumen perencanaan pembangunan yang disusun. Dalam konteks ini diperlukan penyusunan Katalog Data Perencanaan Pembangunan (Katalog Data Renbang) yang sudah benar, berkualitas dan memenuhi prinsip Satu Data Indonesia. Katalog Data Renbang akan menjadi dasar proses penyusunan RPJMN dan RKP. Oleh karena itu, proses bisnis tersebut harus yang menjadi prosedur dan mekanisme yang baku, sistemik dan berkelanjutan yang diterapkan di Bappenas secara konsisten.

Pembiasaan dan Pembudayaan Big Data dan Analitika Data merupakan urgensi berikutnya yang harus dilakukan. Dengan demikian akan tercipta kebiasaan (habbit) baru di Bappenas dalam jangka menengah, yang selanjutnya dalam jangka panjang akan berkembang menjadi budaya (culture) baru akan meningkatkan kualitas kelembagaan Bappenas secara keseluruhan. Pembiasaan dan Pembudayaan Big Data dan Analitika Data akan mempertajam formulasi kebijakan dan perencanaan pembangunan dalam jangka panjang.

Implementasi Pelembagaan Satu Data Indonesia serta Pembiasaan dan Pembudayaan Big Data dan Analitika Data secara substansial dan kumulatif akan meningkatkan "value" dan "leverage" Bappenas baik sebagai lembaga perencanaan pembangunan nasional (planning institution) yang handal dan mumpuni maupun sebagai salah satu lembaga Think Tank pemerintah yang maju, rasional dan profesional. Wallahualam bissawab.

\section{Daftar Pustaka}

Biehn N. (2013). “The Missing V’s in Big Data: Viability and Value. Wired. Available from: http://www.wired.com/insights/2013/05/the-missing-vsin-big-data-viability-andvalue/.

Boyd, D. and Crawford, K. (2012). "Critical Questions for Big Data. Information, Communication, \& Society. 15(5). pp. 662-679.

EDUCBA. (2019). "Data Analytics vs Data Analysis". In www.educba.com.

Gartner. (2014). "IT Glossary Big Data". Available in http://www.gartner.com/itglossary/big-data/.

Grimes, S. (2013) “Big Data: Avoid 'Wanna V' Confusion. Information Week. Available from: http://www.informationweek.com/big-data/big-data-analytics/big-dataavoidwannaconfusion/d/d.

Jacobs, A. (2009). "The pathologies of Big Data". Communications of the ACM. 52(8). pp. $36-44$.

Kraska, T. (2013). "Finding the Needle in the Big Data Systems Haystack". IEEE Internet Computing. 17(1). pp. 84-86.

Loshin, D. (2009). "Big Data Analytics”. Waltham. Morgan Kaufmann. 
Marr, B. (2015) "Why Only One of the 5 Vs of Big Data Really Matters". IBM Big Data \& Analytics Hub. Available from: http://www.ibmbigdatahub.com/ blog/why-onlyone-5-vs-big-data-really-matters.

Mazzei, Mattew J. and Noble, David. (2019). "Big Data and Strategy: Theoretical Foundations and New Opportunities. http://dx.doi.org/10.5772/intechopen.84819.

Megahed, F.M. and Jones-Farmer, L.A. (2013). "A Statistical Process Monitoring Perspective on Big Data”. In Frontiers in Statistical Quality Control. 11th ed. New York. Springer.

McAfee, A. and Brynjolfsson, E. (2012). "Big Data: The Management Revolution”. Harvard Business Review. 90(10). pp.60-68.

Morabito, V. (2015). "Big Data and Analytics: Strategic and Organizational Impacts". Switzerland. Springer.

Porter, M.E. and Heppelmann, J.E. (2014). "How Smart, Connected Products are Transforming Competition”. Harvard Business Review. 92(11). pp. 64-88.

Republik Indonesia. (2019). "Peraturan Presiden Republik Indonesia Nomor 39 Tahun 2019 Tentang Satu Data Indonesia”.

Riahi, Youssra and Riahi, Sara. (2016). "Big Data Analytics: Challenges and Applications for Text, Audio, Video, and Social Media Data”. International Journal on Soft Computing, Artificial Intelligence and Applications (IJSCAI). Vol. 5. No. 1. February.

Riahi, Youssra and Riahi, Sara. (2018). "Big Data and Big Data Analytics: Concepts, Types and Technologies”. International Journal of Research and Engineering. Vol. 5. No. 9. September-October. pp. 524-528.

UN Global Pulse. (2012). "Big Data for Development: Challenges and Opportunities".

van Rijmenam, M. (2014). "Think Bigger: Developing a Successful Big Data Strategy for Your Business". New York. Amacom.

Wu, X. Zhu, X. and Wu, G. (2014). "Data Mining with Big Data”. IEEE TKDE. 26. pp. 97107.

Zikopoulos, P. Eaton, C. de Roos, D. Deutsch, T. Lapis, G. (2012). "Understanding Big Data: Analytics for Enterprise Class Hadoop and Streaming Data”. New York. McGrawHill. 